\title{
A Twin Unidirectional Impulse Turbine for Wave Energy Conversion-Effect of Fluidic Diode on the Performance
}

\author{
Shinya Okuhara', Manabu Takao ${ }^{2}$, Hideki Sato ${ }^{3}$, Akiyasu Takami' ${ }^{2}$, Toshiaki Setoguchi ${ }^{4}$ \\ ${ }^{1}$ Support Center for Practical Education, National Institute of Technology, Matsue College, Matsue, Japan \\ ${ }^{2}$ Department of Mechanical Engineering, National Institute of Technology, Matsue College, Matsue, Japan \\ ${ }^{3}$ Advanced Engineering Faculty, National Institute of Technology, Matsue College, Matsue, Japan \\ ${ }^{4}$ Institute of Ocean Energy, Saga University, Saga, Japan \\ Email: takao@matsue-ct.jp
}

Received 25 October 2014; revised 17 November 2014; accepted 8 December 2014

Copyright (C) 2014 by authors and Scientific Research Publishing Inc.

This work is licensed under the Creative Commons Attribution International License (CC BY).

http://creativecommons.org/licenses/by/4.0/

c) (i) Open Access

\begin{abstract}
As a system using a conventional unidirectional air turbine in oscillating water column (OWC) based on a wave energy plant, a twin unidirectional impulse turbine topology has been suggested in previous studies. However, the average efficiency of the suggested twin turbine is considerably lower than that of a conventional unidirectional turbine in this topology because reciprocating air flow can't be rectified adequately by a unidirectional turbine. In order to improve the efficiency, using fluidic diode is discussed. In this study, two different fluidic diodes were discussed by computational fluid dynamics (CFD) and a wind tunnel test. Further, its usefulness is discussed from a view point of the turbine efficiency. The fluidic diode was shown to improve rectification of the topology. However, it needs more improvement in regards to its energy loss in order to enhance the turbine efficiency.
\end{abstract}

\section{Keywords}

Fluidic Diode, Twin Unidirectional Turbine, Wave Energy Conversion, Oscillating Water Column

\section{Introduction}

As an air turbine equipped with oscillating water column (OWC) based wave energy plant, a rectification-valve system using a conventional unidirectional turbine has been invented. However, this system has problems with the durability of the valves and the complexity of the mechanism. Moreover, it has a major fault that the valves 
must be large so as to produce high output. Therefore, a twin unidirectional impulse turbine topology has been suggested in previous studies in order to use conventional unidirectional turbines without a rectification valve [1] [2]. The topology is composed of two unidirectional impulse turbines coupled with an electrical generator, as shown in Figure 1. However, the past study indicated that the average efficiency of the topology was shown to be low, when the performance prediction of the topology in oscillating airflow was carried out by means of quasisteady analysis [1]. Further, the cause of the low efficiency is that part of the air flow gets through the unidirectional impulse turbine in the direction of low efficiency [1].

In this study, a fluidic diode [2] [3] is adopted in order to suppress the air flow rate into the inefficient turbine in a twin unidirectional impulse turbine topology for wave energy plant, and the effect of the fluidic diodes on the performance of twin unidirectional impulse turbine topology is investigated by a wind tunnel test and computational fluid dynamics (CFD). Further, its usefulness is discussed from a view point of the turbine efficiency.

\section{Twin Unidirectional Impulse Turbine Topology and Fluidic Diode}

In a twin unidirectional impulse turbine topology, two unidirectional impulse turbines coupled with an electric generator are installed as shown in Figure 1. In this study, when air flow gets through a turbine or fluidic diode, the flow direction that indicates smaller flow resistance is described as "forward flow", and the flow direction that indicates larger flow resistance is described as "reverse flow". Index "f" stands for "forward flow" and index " $r$ " stands for reverse flow. A turbine in forward flow and it in reverse flow are respectively described as "forward turbine" and "reverse turbine".

The principle of a twin unidirectional impulse turbine topology is as followed. Oscillating air flow is produced in an air chamber. Then, it is rectified into a forward turbine that has the high efficiency by a reverse turbine. Consequently, electricity is produced with high efficiency. However, the average efficiency of the topology is considerably lower than that of a unidirectional impulse turbine because part of the air flow gets through the reverse turbine resulting in the efficiency of energy conversion being very low [1]. As a way of improving this fault, rectifying an oscillating air flow by installing fluidic diode downstream from a forward turbine is suggested [2].

Fluidic diodes indicate different pressure differences between the front and back against different flow directions. Figure 2 shows the fluidic diodes adopted in this study. Figure 2(a) shows the fluidic diode which has a shape of a conical nozzle (Type I). The projection length is $125 \mathrm{~mm}$ and the larger diameter is $240 \mathrm{~mm}$. A wind tunnel test and CFD were carried out by varying the taper angle $\theta$. Then, both results were compared. Figure 2(b) shows the special type fluidic diode (Type II) which is designed by referring a fluidic diode suggested in references [2]. The flow passage is composed of a bluff body (B) that has a hollow $(\mathrm{H})$ rear, a toroidal region $(\mathrm{T})$ and a conical nozzle region $(\mathrm{N})$. In this study, CFD for Type II was carried out by changing the taper angle $\theta$ of the conical nozzle region.

\section{Experiments and Computational Method}

For CFD software, SCRYU/Tetra of Software Cradle Co., Ltd. was used. The governing equation was Reynolds averaged Navier-Stokes equation and turbulence model was a standard $k-\varepsilon$ model. The working fluid was incompressible air at $20^{\circ} \mathrm{C}$. The analyzed region was a flow passage composed of tube and fluidic diodes. The analysis region of Type I consisted of approximately 1,500,000 lattices and the analysis region of Type II consisted of approximately 6,470,000 lattices. As a boundary condition, the inner wall of the tube and fluidic diode were in a non-slip boundary condition, and the inlet had an inflow in a constant flow rate. The outlet was opened to the atmosphere. The forward-flow and reverse-flow pressure differences $\left(\Delta p_{\mathrm{f}}\right.$ and $\left.\Delta p_{\mathrm{r}}\right)$ were examined in a position far enough from the fluidic diode. In order to calculate the effects of the taper angles $\theta$ on $R_{\mathrm{D}}$, CFD was executed by varying $\theta$ from 10 to 60 in 10 degree intervals in Type I and $\theta$ from 0 to 60 in 10 degree intervals in Type II.

In this study, the rectification property of the Type I in steady flow was examined by a wind tunnel test so as to indicate the validity of CFD. In the wind tunnel test, the suction test apparatus was composed of a centrifugal blower, the fluidic diode Type I and a tube of which the internal diameter was $240 \mathrm{~mm}$ as shown in Figure 3. As an experimental method, the blower generates a steady flow in the fluidic diode. The flow rate $Q$ was measured by a Pitot tube (OKANO WORKS, LK-0). The pressure in the settling chamber was measured by a pressure detector (OKANO WORKS, POP202) in order to examine the pressure differences $\Delta p_{\mathrm{f}}$ and $\Delta p_{\mathrm{r}}$ between the front 


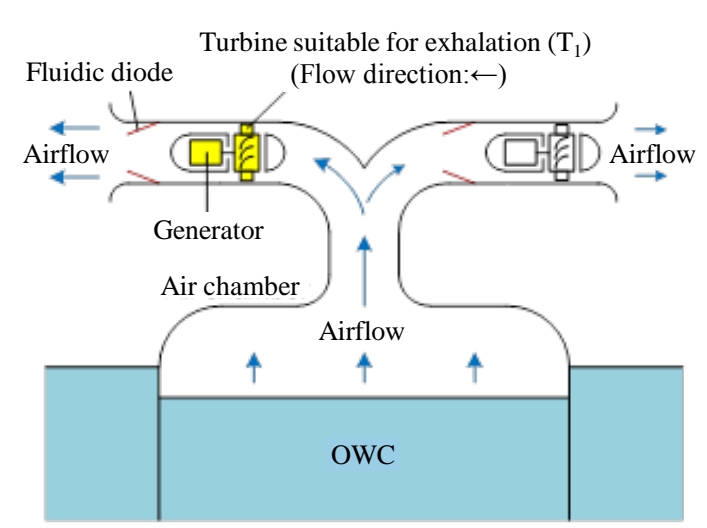

(a)

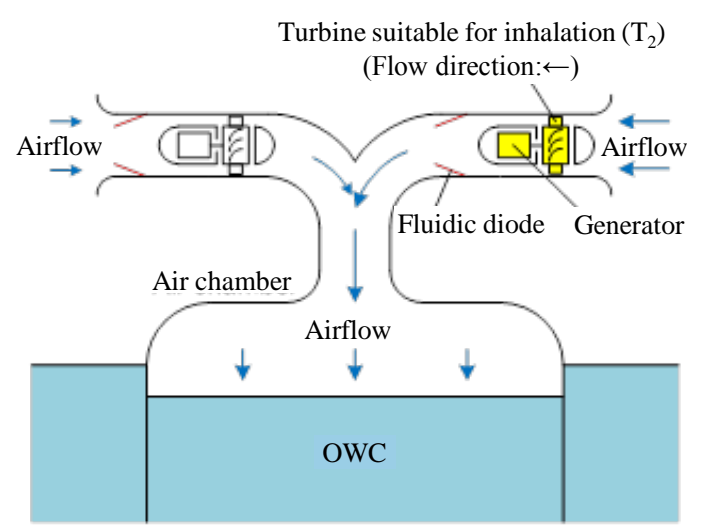

(b)

Figure 1. Principle of twin impulse turbine for wave energy conversion: (a) Exhalation; (b) Inhalation.

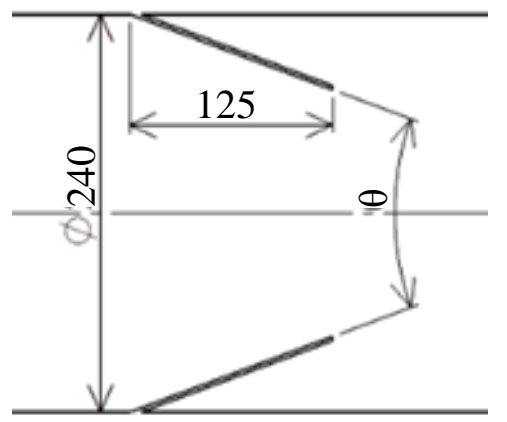

(a)

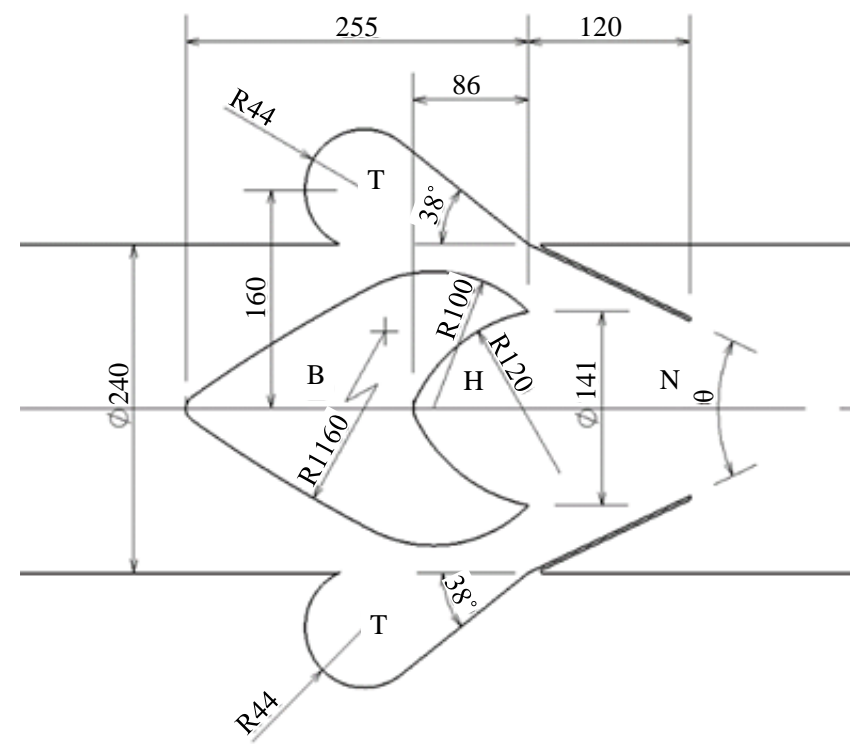

(b)

Figure 2. Tested fluidic diode: (a) Type I; (b) Type II.

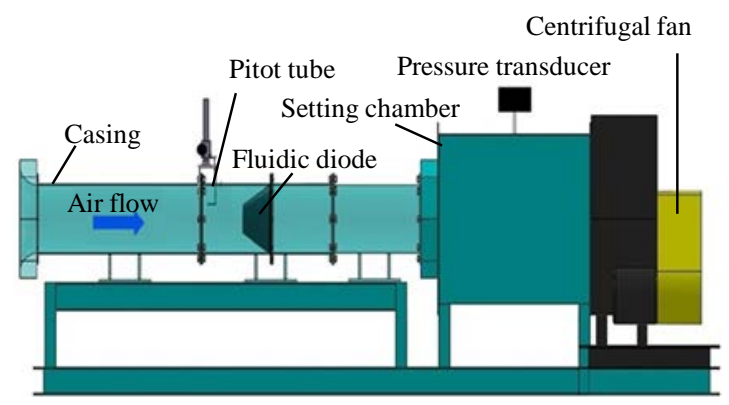

Figure 3. Test apparatus.

and the back of the fluidic diode in both the forward and reverse flow.

The performance of the fluidic diode is evaluated by the pressure ratio $R_{\mathrm{D}}$ and the pressure coefficients $C_{\mathrm{pf}}$, $C_{\mathrm{pr}}$. The definitions of these parameters are as follows:

$$
R_{\mathrm{D}}=\Delta p_{\mathrm{r}} / \Delta p_{\mathrm{f}}
$$




$$
\begin{gathered}
C_{\mathrm{pf}}=\Delta p_{\mathrm{f}} /\left(\rho v^{2} / 2\right) \\
C_{\mathrm{pr}}=\Delta p_{\mathrm{r}} /\left(\rho v^{2} / 2\right)
\end{gathered}
$$

where $\rho$ and $v$ denote the density of air and axial flow velocity respectively.

\section{Results and Discussion}

Figure 4 shows the effect of the taper angle $\theta$ on the pressure coefficients $C_{\mathrm{pf}}$ and $C_{\mathrm{pr}}$, respectively in both forward and reverse flow in Type I, as the results to the CFD and the wind tunnel test. In the figure, flow rates $Q$ are $0.320 \mathrm{~m}^{3} / \mathrm{s}$ in the calculation and $0.308 \mathrm{~m}^{3} / \mathrm{s}$ in the experiment. In the figure, both results of calculation and experiment are matched well. In Figure 4, both $C_{\mathrm{pf}}$ and $C_{\mathrm{pr}}$ increase as $\theta$ increases.

Figure 5 shows the effect of the taper angle $\theta$ on the pressure ratio $R_{\mathrm{D}}$ of Type I as the result to the CFD. The $R_{\mathrm{D}}$ becomes the maximum $R_{\mathrm{D}}=2.00$ after it increases with $\theta$. The rectification of cascades geometry profitable for twin unidirectional impulse turbine topology [4] [5] in the maximum efficiency was calculated by the $C_{\mathrm{A}}-\phi$ curve ( $C_{\mathrm{A}}$ : input coefficient, $\phi$ : flow coefficient). The value is $R_{\mathrm{D}}=2.63$. The maximum $R_{\mathrm{D}}$ of Type I is shown to be lower than that of the unidirectional impulse turbine in Figure 7. Therefore, this indicates that the rectification of Type I was lower than that of the unidirectional impulse turbine.

On the other hand, Figure 6 shows the effect of the taper angle $\theta$ on the pressure ratio $R_{\mathrm{D}}$, the pressure coefficients $C_{\mathrm{pf}}$ and $C_{\mathrm{pr}}$, respectively in both forward and reverse flow in Type II. The tendency of the graph is similar to that of Type I. The maximum $R_{\mathrm{D}}$ of Type II is 5.03 in the taper angle $\theta=40^{\circ}$. The maximum $R_{\mathrm{D}}$ of Type II is much higher than that of the unidirectional impulse turbine, as shown in Figure 7. Therefore, rectification of the twin unidirectional impulse turbine topology can be improved by installing Type II. However, the efficiency of a forward turbine coupled with Type II is lower than that of the only forward turbine because the additional pressure loss is caused by Type II in the forward flow. Therefore, Type II must be improved to decrease the flow resistance in the forward flow.

Figure 8 and Figure 9 show the velocity vector and pressure distribution respectively around Type II in both the forward and reverse flow. Forward flow goes from left to right. Reverse flow goes from right to left. In the forward flow, the cause of main pressure loss is the narrower flow passage of the conical nozzle. In the reverse flow, the causes of main pressure loss are the narrower flow passage of the conical nozzle, the hollow of the bluff body and the toroidal part. Figure 6 shows that Type II doesn't have sufficient rectification function without the part of conical nozzle. However, it has main flow resistance in the forward flow. On the other hand, the toroidal part doesn't have a large flow resistance in the forward flow while it has large flow resistance in the reverse flow. The route of the forward flow is different from that of the reverse flow because of the each flow separation. Therefore, changing the flow route by making use of flow separation, so that forward flow avoids stagnation zones which reverse flow goes to, is effective.

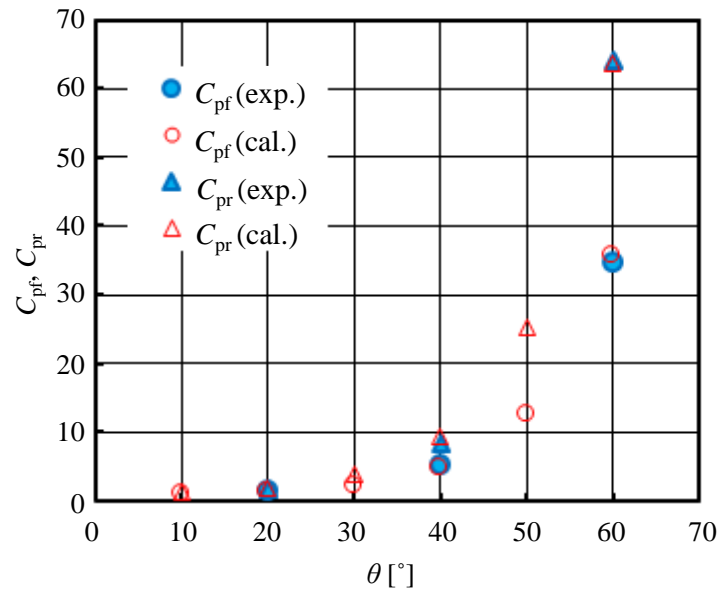

Figure 4. Effect of taper angle on pressure coefficient (Type I). 


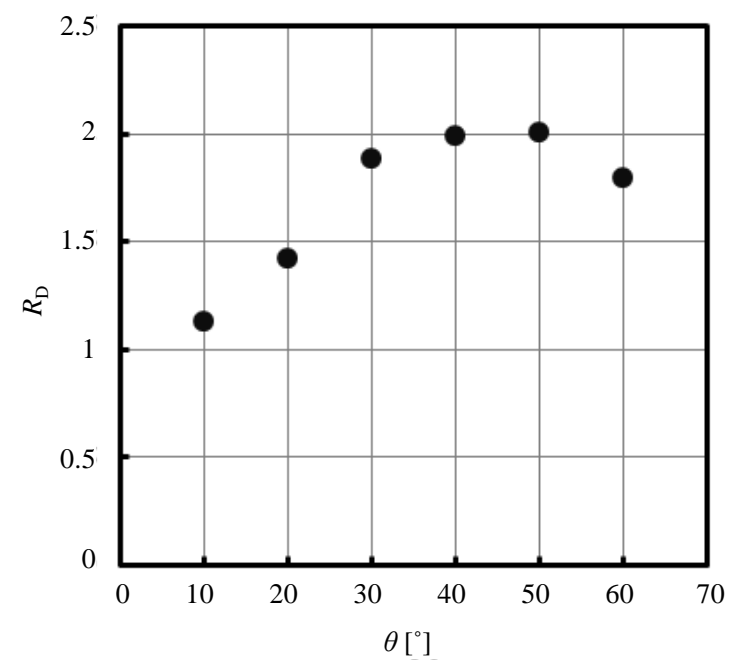

Figure 5. Effect of taper angle on pressure ratio (Type I, calculation).

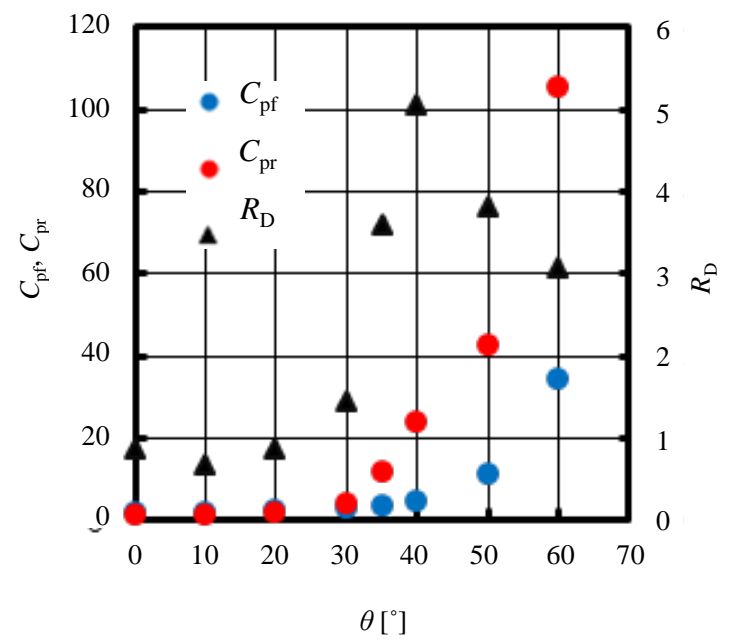

Figure 6. Effect of taper angle on pressure coefficient and pressure ratio (Type II, calculation).

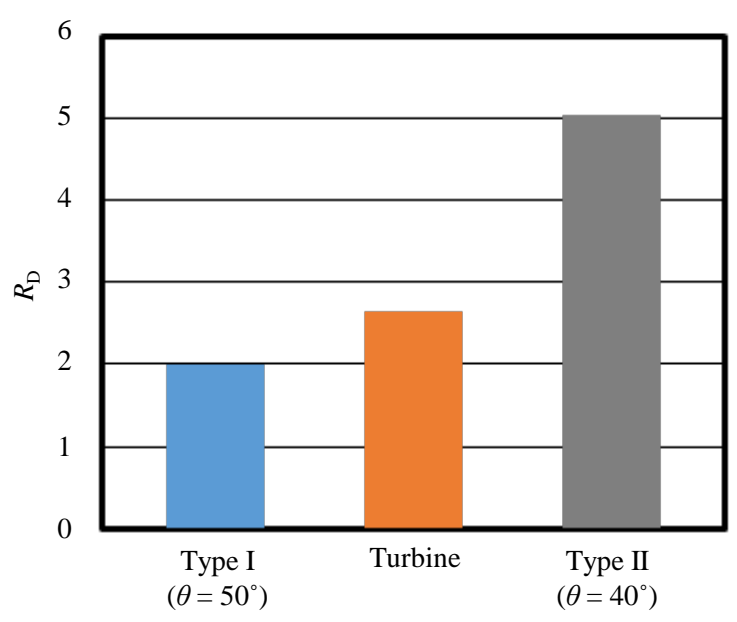

Figure 7. Comparison of $R_{\mathrm{D}}$. 


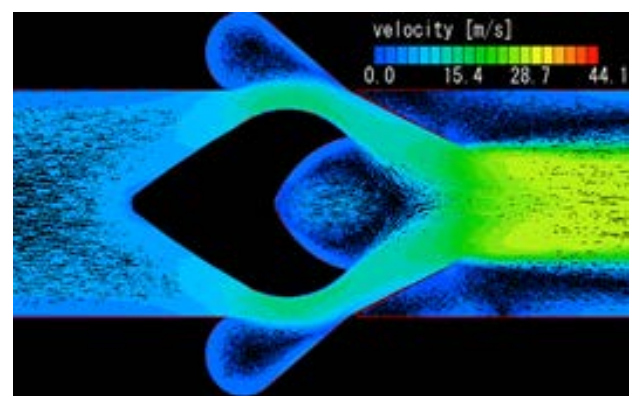

(a)

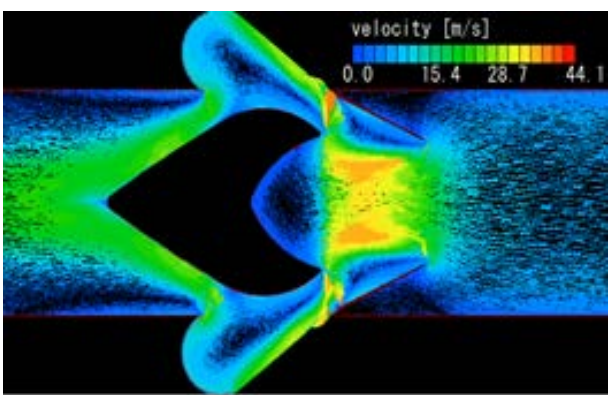

(b)

Figure 8. Flow velocity in fluidic diode of Type II $\left(\theta=40^{\circ}\right)$ : (a) Forward flow; (b) Reverse flow.

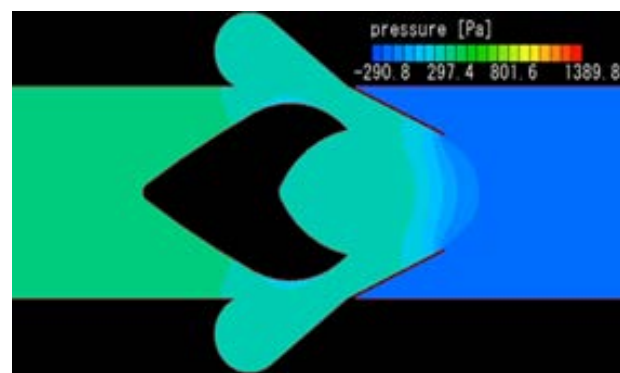

(a)

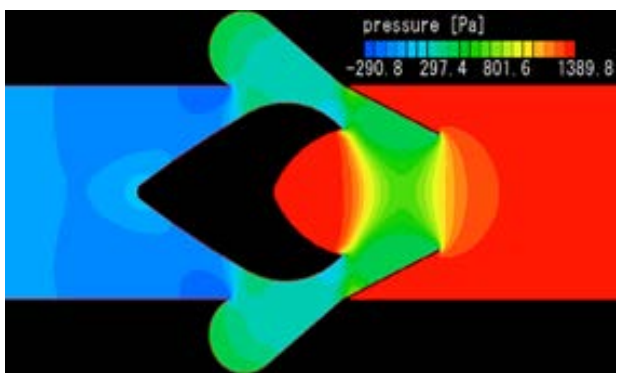

(b)

Figure 9. Pressure distribution in fluidic diode of Type II $\left(\theta=40^{\circ}\right)$ : (a) Forward flow; (b) Reverse flow.

\section{Conclusion}

In this study, the effect of the fluidic diodes on the performance of twin unidirectional impulse turbine topology was discussed by using CFD and wind tunnel testing. As a result, fluidic diodes, which have a shape of conical nozzle (Type I) are shown to be inadequate for this turbine topology. On the other hand, a special type of fluidic diode (Type II), which is designed from the original shape by the authors, was shown to have the possibility of improving performance of this turbine topology. However, from a view point of the turbine efficiency, it needs improvement in order to diminish the pressure difference in the forward flow.

\section{Acknowledgements}

This study was performed as Grant-in-Aid for Scientific Research (B) (No. 24360362) supported by Japan Society for the Promotion of Science (JSPS). The second author wishes to thank JSPS for their financial help in conducting this study.

\section{References}

[1] Takao, M., Takami, A., Okuhara, S. and Setoguchi, T. (2011) A Twin Unidirectional Impulse Turbine for Wave Energy Conversion. Journal of Thermal Science, 20, 394-397. http://dx.doi.org/10.1007/s11630-011-0486-1

[2] Dudhgaonkar, P.V., et al. (2011) Fluidic Components for Oscillating Water Column Based Wave Energy Plants. Proceedings of ASME-JSME-KSME Joint Fluids Engineering Conference 2011, Paper No. AJK2011-07035.

[3] Takebayashi, M., Akazume, A., Yokoyama, K. and Iwata, H. (1984) Discharge Characteristics of a Oil Feeder Pump with Nozzle Type Fluidic Diodes. Transactions of JSME (Series B), 51, 255-261. (In Japanese)

[4] Okuhara, S., Takao, M., Takami, A. and Setoguchi, T. (2012) A Twin Unidirectional Impulse Turbine for Wave Energy Conversion-Effect of Guide Vane Solidity on the Performance. Open Journal of Fluid Dynamics, 2012, 343347. http://dx.doi.org/10.4236/ojfd.2012.24A043

[5] Takao, M., Setoguchi, T., Kaneko, K., Kim, T.H., Maeda, H. and Inoue, M. (2002) Impulse Turbine for Wave Power Conversion with Air Flow Rectification System. International Journal of Offshore and Polar Engineering, 12, 142146. 


\section{Nomenclature}

$C_{\mathrm{A}}$ : Input coefficient

$C_{\mathrm{p}}$ : Pressure coefficient $\left\{C_{\mathrm{p}}=\Delta p /\left(\rho v^{2} / 2\right)\right\}$

$Q$ : Flow rate $\left(\mathrm{m}^{3} / \mathrm{s}\right)$

$R_{\mathrm{D}}$ : Ratio of pressure difference $\left(=\Delta p_{\mathrm{r}} / \Delta p_{\mathrm{f}}\right)$

$v$ : Axial flow velocity $(\mathrm{m} / \mathrm{s})$

$\Delta p$ : Pressure difference (Pa)

$\phi$ : Flow coefficient

$\theta$ : Taper angle of conical nozzle ( $\left(^{\circ}\right)$

$\rho$ : Air density $\left(\mathrm{kg} / \mathrm{m}^{3}\right)$

\section{Subscripts}

f: Forward flow $r$ Reverse flow 
Scientific Research Publishing (SCIRP) is one of the largest Open Access journal publishers. It is currently publishing more than 200 open access, online, peer-reviewed journals covering a wide range of academic disciplines. SCIRP serves the worldwide academic communities and contributes to the progress and application of science with its publication.

Other selected journals from SCIRP are listed as below. Submit your manuscript to us via either submit@scirp.org or Online Submission Portal.
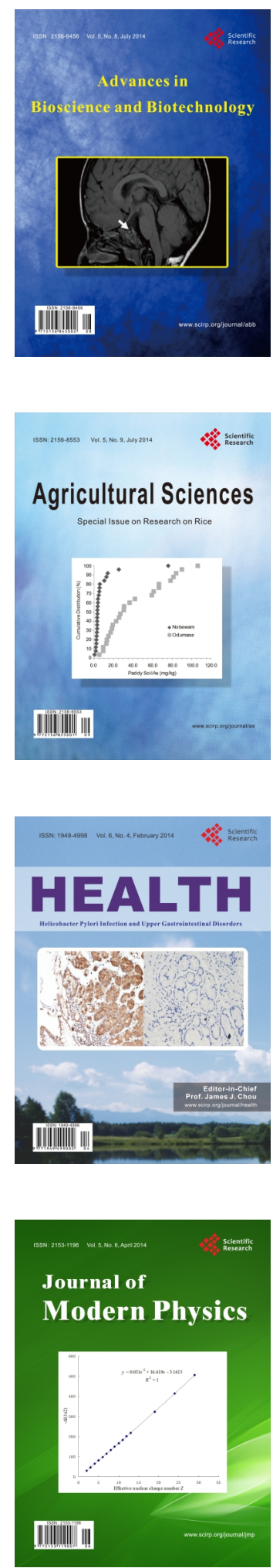
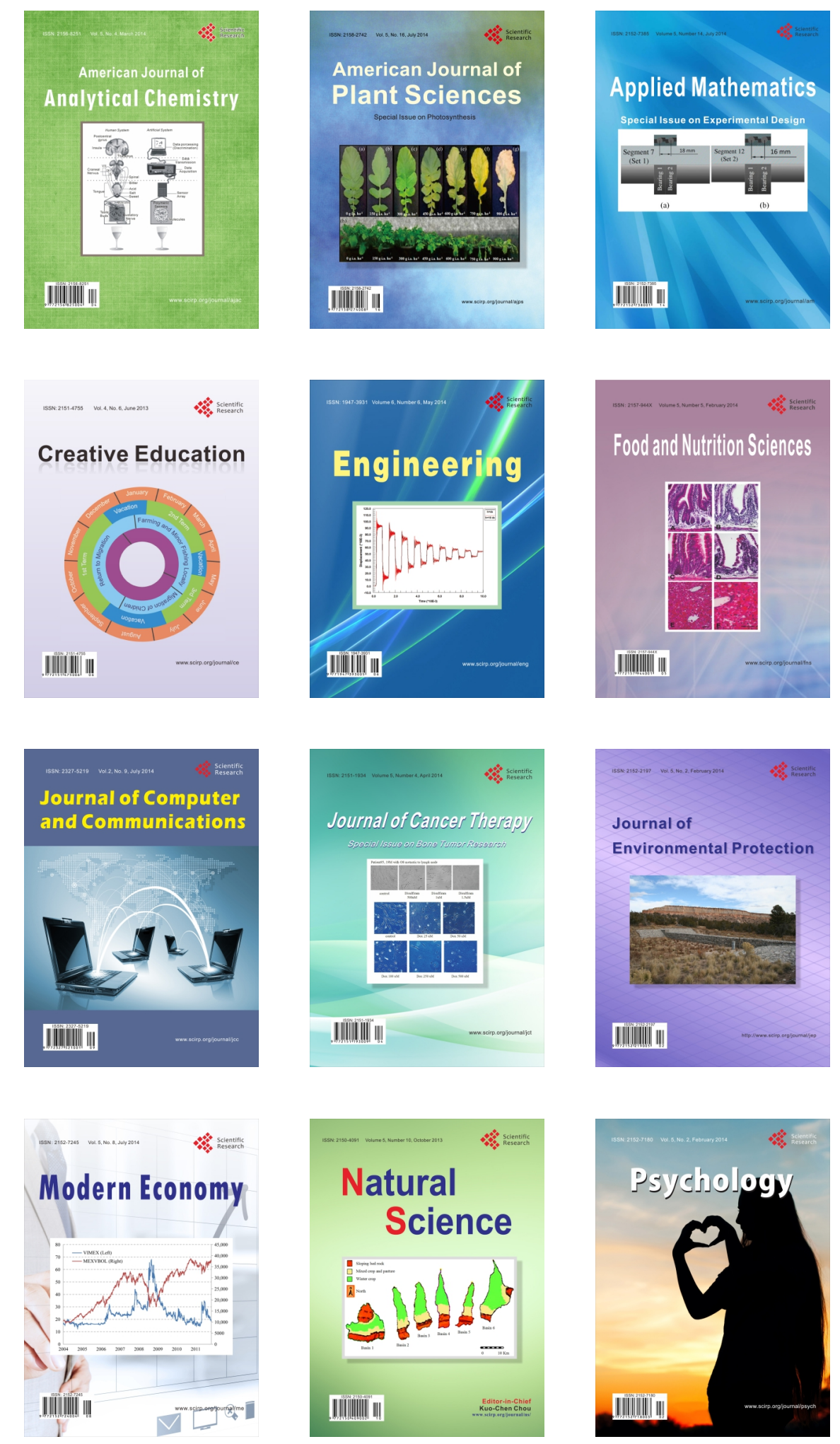